\title{
Legal and ethical implications in the evaluation and management of sports-related concussion
}

Matthew P. Kirschen, $\mathrm{MD}, \mathrm{PhD}$

Amy Tsou, MD

Sarah Bird Nelson, JD

James A. Russell, DO, FAAN

Daniel Larriviere, MD, JD, FAAN

On behalf of the Ethics, Law, and Humanities Committee, a Joint Committee of the American Academy of Neurology, American Neurological Association, and Child Neurology Society

Correspondence to Dr. Kirschen:

kirschenm@chop.edu

Editorial, page 300

Supplemental data at Neurology.org

\section{ABSTRACT}

Objective: To examine the ethical and legal issues physicians face when evaluating and managing athletes with sports-related concussions, and to offer guidance to physicians as they navigate these situations.

Results: This position paper reviews and compares the components of sports-related concussion laws, including education, removal from play, and clearance for return to play. It highlights the challenges privacy laws present relevant to providing care to concussed athletes and suggests ways to help physicians overcome these obstacles. The report also explores the ethical considerations physicians should bear in mind as they evaluate and manage concussed athletes, addressing them through a framework that includes considerations of professionalism, informed decision-making, patient autonomy, beneficence, nonmaleficence, conflicts of interest, and distributive justice.

Conclusions: Physicians caring for concussed athletes have an ethical obligation to ensure that their primary responsibility is to safeguard the current and future physical and mental health of their patients. Physicians have a duty to provide athletes and their parents with information about concussion risk factors, symptoms, and the risks for postconcussion neurologic impairments. Physicians should facilitate informed and shared decision-making among athletes, parents, and medical teams while protecting athletes from potential harm. Additionally, including concussion evaluation and management training in neurology residency programs, as well as developing a national concussion registry, will benefit patients by the development of policies and clinical guidelines that optimize prevention and treatment of concussive head injury. Neurology ${ }^{\circledR}$ 2014;83:352-358

\section{GLOSSARY}

AAN = American Academy of Neurology; CDC = Centers for Disease Control and Prevention; HIPAA = Health Insurance Portability and Accountability Act.
Over the past few years, sports-related concussion has become a major health concern in the United States. The Centers for Disease Control and Prevention (CDC) estimates that 1.6-3.8 million sports-related concussions occur each year. ${ }^{1}$ Although a majority of these injuries occur while playing football, concussions are also common in other contact sports, like soccer, lacrosse, hockey, rugby, and basketball..$^{2-5}$ Concussions can have devastating effects, such as shortterm impairments in athletes' cognitive and athletic performance. Repetitive concussions, and even subconcussive impacts, have been associated with long-term impairments in neurocognitive functioning, behavioral problems, premature dementia, and chronic traumatic encephalopathy. ${ }^{5-12}$
Evaluating and managing sports-related concussion raises a variety of distinctive ethical and legal issues for physicians, especially relating to return-to-play decisions. A recent survey conducted by the American Academy of Neurology (AAN) demonstrated that while a majority of neurologists see patients with sportsrelated neurologic concerns, most do not receive formal or informal training regarding concussion. ${ }^{13}$ The purpose of this position paper is to explore the ethical and legal issues physicians face when evaluating and managing athletes with sports-related concussions, and to offer guidance to physicians as they navigate these situations. This report is primarily intended for physicians who evaluate and manage youth and amateur athletes with a suspected concussion, and to serve as a compendium
From the Division of Neurology (M.P.K.), Department of Pediatrics, and Department of Anesthesia and Critical Care Medicine, The Children's Hospital of Philadelphia, Perelman School of Medicine at the University of Pennsylvania; the Emergency Care Research Institute and Philadelphia Veterans Affairs Medical Center (A.T.), PA; the American Academy of Neurology (S.B.N.), Minneapolis, MN; the Department of Neurology (J.A.R.), Lahey Clinic, Tufts University School of Medicine, Boston, MA; and the Ochner Neuroscience Institute (D.L.), Ochsner Medical Center, New Orleans, LA.

Members of the AAN Ethics, Law, and Humanities Committee and AAN staff who participated in development of this report are listed on the Neurology ${ }^{\circledR}$ Web site at Neurology.org.

Go to Neurology.org for full disclosures. Disclosures deemed relevant by the authors, if any, are provided at the end of this article. 
to current concussion diagnosis and management guidelines that have been produced by the AAN. ${ }^{14}$ Readers may also be interested in reviewing guidelines produced by the American Academy of Pediatrics, American Medical Society for Sports Medicine, and others. ${ }^{15-18}$

Physicians should be aware that these clinical concussion guidelines are largely derived from data generated from high school and university athletes. There are limited data from pediatric populations to determine concussion risk factors, validity and reliability of diagnostic tests, and interventions that purport to alter the natural history of concussion recovery or reduce long-term sequelae of concussion.

LEGAL CONTEXT Concussion laws. While federal legislation specific to sports-related concussion has been introduced, ${ }^{19,20}$ there are currently no federal sports-related concussion laws. States, however, have responded to concerns stemming from sports-related concussion by passing laws intended to protect young athletes. As of January 2014, all 50 states (plus the District of Columbia) have adopted youth sports concussion laws. ${ }^{21}$ The first of these laws-and the one that is considered model legislation-went into effect in 2009 in Washington and includes 3 main components:

1. Education: Each school district's board of directors must work with the state's interscholastic activities association to develop guidelines and other materials to inform and educate coaches, athletes, and their parents or guardians of the nature and risk of concussion and head injury, including continuing to play after concussion or head injury. An athlete and his or her parent or guardian must sign a concussion and head injury information sheet each year before the athlete can practice or compete in his or her sport.

2. Removal from play: If an athlete is suspected of having sustained a concussion during practice or a game, the athlete must be removed from competition at that time.

3. Clearance for return to play: An athlete who has been removed from play may not return to play until a licensed health care provider trained in the evaluation and management of concussion evaluates and provides written clearance for the athlete to return to play. ${ }^{22}$

Most statutes address these 3 components, but there are some noteworthy differences among the laws. For example, statutes differ as to who may provide clearance to return to play: some states only allow physicians to make this decision, while others permit athletic trainers, nurse practitioners, and physician assistants to do so. States do not uniformly require that individuals providing clearance be trained in the evaluation and management of concussion. In addition, some states require written clearance to be given, while others require only verbal clearance. Liability protection for evaluators also varies among statutes, with some states affording protection to volunteers who provide clearance in certain contexts. Thus, it is important for physicians to be cognizant of both their state law and laws in states where their patients reside so that they are familiar with their legal responsibilities and protections. ${ }^{23}$

While not flawless, state concussion laws are beneficial to youth athletes. The low removal-from-play threshold present in the statutes will likely reduce the number of athletes who may otherwise continue to play with a concussion and increase the number of athletes who receive appropriate evaluation and care. The existence of these laws, in addition to their educational requirements, should encourage coaches, parents, and athletes across the country to take the risks associated with concussion more seriously. Unfortunately, the reporting schemes established by the laws may create potential conflicts between athletes and their care providers, and the laws are generally silent on the issue of protecting athletes from the harmful effects of repeated concussions.

Privacy laws. In addition to state concussion laws, physicians who perform concussion evaluations must consider federal and state privacy laws. The federal Health Insurance Portability and Accountability Act (HIPAA), as well as many state privacy laws, restricts providers from sharing personal health information without patient consent. These restrictions can present challenges for physicians in the context of athlete-patients who want to return to play prematurely. For example, a concussed athlete may disregard his or her doctor's recommendation to refrain from participation and "doctor shop" until he or she finds a physician who will provide the necessary clearance. The athlete may also request that the physician's evaluation and denial for clearance to return to play remain confidential. While this may seem extreme, many athletes will jeopardize their physical and mental health to continue competing, as evidenced by the frequent underreporting of concussion symptoms to avoid removal from play despite receiving education about concussion risks. ${ }^{24}$ Thus, the evaluating physician could find himself or herself in the difficult position of being legally restricted from sharing a concussion evaluation with the athlete's coaches and school personnel, even though making such a disclosure might be in the best interest of the athlete's health.

Fortunately, waivers offer one way for physicians to avoid this situation. Some institutions (e.g., school districts or athletic organizations) have policies that require athletes to sign waivers at the start of the season that allow information to be shared between physicians, coaches, and other team or school staff. These waivers typically apply only to physicians specifically 
affiliated with school athletic departments. A physician without any school affiliation might require an athletepatient or his or her parents to sign a consent form that specifically allows the physician to communicate the results of a concussion evaluation with team personnel before the physician begins an assessment. As with the institution-generated waivers, this approach would satisfy HIPAA and state laws that require written patient consent for the release of health information.

If having athletes sign HIPAA waivers is not feasible, physicians may still be able to disclose an athlete's personal health information to a coach. HIPAA does allow physicians to disclose personal health information when the physician has a good-faith basis to believe the disclosure is "necessary to prevent or lessen a serious and imminent threat to the health or safety of a person." 25 This is a very limited exception that is highly dependent on the facts of a given situation. Thus, if a physician wants to entertain this disclosure option, he or she should consult an attorney familiar with HIPAA and any applicable state privacy laws.

ETHICAL CONSIDERATIONS Professionalism. The AAN Code of Professional Conduct states that "The neurologist must practice only within the scope of his/ her training, experience, and competence. The neurologist should provide care that represents the prevailing standards of neurologic practice." ${ }^{26}$ It is, therefore, essential that physicians responsible for either the sideline or subsequent medical care of athletes who have sustained sports-related head trauma have adequate training and experience in the recognition and evaluation of the existence and severity of potential brain injury. Physicians should also be familiar with current management guidelines, ${ }^{14-18}$ such as those recently released by the $\mathrm{AAN},{ }^{14}$ as well as national (e.g., CDC's Heads Up initiative) and state-specific (e.g., Pennsylvania Department of Education's BrainSTEPS) programs to raise awareness and improve concussion education. As previously mentioned, some state laws specify training requirements for physicians who are making return-to-play recommendations for concussed athletes. Adult neurologists may treat pediatric patients with concussions, and vice versa, if managing these patients is within the physician's scope of knowledge and practice, and is approved by their credentialing institution. Since neurology training programs have only recently begun to offer formal training in the evaluation and management of concussion, most practicing physicians will qualify by virtue of experience or by participating in continuing medical education courses covering this topic.

Informed decision-making and respecting autonomy. Respect for autonomy emphasizes the importance of allowing patients and parents to participate in making medical decisions, including decisions about returning to play, and the right to refuse recommended treatment. All physicians have an ethical duty to educate their athlete-patients and the patients' parents about concussion. Specifically, physicians have a duty to inform them (in understandable language) about the evidence for potential short- and long-term neurocognitive and neurobehavioral risks associated with single and multiple concussions as well as common clinical concussion manifestations. This duty to educate is independent of whether an athlete has previously had a concussion. Physicians may choose to discuss data that demonstrate reduced learning and memory performance after playing contact sportseffects thought to be secondary to the accumulation of multiple subconcussive head impacts - even when overt concussions are not reported. ${ }^{27}$ Effective concussion education exists in multiple forms, including videos, Web sites, lectures, and handouts. As a result of concussion laws, many schools and physicians now require athletes and parents to sign paperwork affirming that they understand the risks of concussion before the athlete participates in a sport.

There are at least 2 circumstances where a surrogate may be required for decision-making after concussive head injury. An acute concussive injury may transiently compromise an athlete's cognitive ability to such a degree that he or she will lack capacity to make a decision regarding his or her medical care or participation in research studies. Physicians have an ethical obligation to protect their patients in these situations, and may need to rely on family or athletic staff to ensure the patient's safety. Researchers who seek to enroll acutely concussed individuals in studies should consider obtaining informed consent from potential subjects or their proxies (usually parents for minor children) before the start of an athletic season in order to adequately balance the competing obligations of research subject protection and study enrollment.

Physicians should clarify whether health information will be shared with parents, patients, coaches, trainers, and other team or school personnel at the time they initiate care. Providing patients and their parents with information to allow them to make truly informed decisions about their concussion management, and return to play in particular, is a key component of protecting patient autonomy and promoting shared decision-making. Since potential athletic scholarships may influence athletes' return-to-play decisions, these patients and their parents may benefit from being referred to resources that detail the probability of receiving of such awards. ${ }^{28}$

In those instances in which the athlete is a minor, parents or legal guardians will serve as medical decisionmakers for their children. In rare cases, minors can make medical decisions for themselves if they have been 
granted the legal status of emancipation or have been deemed a mature minor for the purpose of making medical decisions. ${ }^{29}$ Situations in which minors are deemed to be fully or partially emancipated are determined by statute and vary from state to state. Limited literature suggests that an adolescent who is at least 14 years old may have the same ability to make health care decisions as an adult. ${ }^{30}$

Cases may arise in which the opinions of an athlete and parent diverge. In this situation, the physician should be aware that coercive forces from other parties, such as coaches, teachers, or teammates, may be exerting undue pressure on the athlete. Providers should also consider the possibility that athletes or their parents may harbor ulterior motives for wishing to be evaluated for postconcussive symptoms, such as requesting academic accommodations, needing an explanation for athletic or academic performance that does not meet expectations, or acquiring neuropsychotropic medications. In these situations, the physician's perspective may be helpful to ensure that medical decisions preserve the best long-term interest of the athlete.

Beneficence and nonmaleficence. The corollary goals of beneficence and nonmaleficence (do no harm) are fundamental to any ethical framework. ${ }^{31}$ When managing athletes who have sustained a concussion, physicians must consider the current and future best interests of the patient. While the long-term effects from a single concussion are unclear, repetitive head injuries have been associated with chronic neurocognitive deficits, neuropsychiatric dysfunction, and neurobehavioral impairments. ${ }^{32,33}$

Two important factors may increase an athlete's risk of harm. First, compared to older athletes, younger athletes are at increased risk for more severe symptoms, cognitive deficits, and a prolonged recovery from concussion. ${ }^{34,35}$ Second, the probability of harmful short- and long-term sequelae from concussion likely increases with the number of concussions an athlete sustains. ${ }^{36,37}$ Thus, the physician's ethical duty to safeguard all athletes, particularly younger athletes, from the risks of additional concussions increases with each injury.

Many considerations could lead an athlete or his or her parent to prefer premature return to play after a concussion. How might physicians balance respect for patient autonomy and their duty to attempt to protect their patients from harm? Providers should explore and be sensitive to the many factors motivating an athlete to return to play despite the athlete's acknowledgement of the risks of further (and potentially permanent) neurologic impairment. These factors may include career aspirations, a commitment to a sport, school, or team, or pressure to meet expectations from family, teammates, or a coach.

However, despite these important considerations, athletes, and particularly adolescent athletes, may not truly understand the risks of potential long-term sequelae of concussion. Thus, restricting concussed athletes from prematurely returning to play, or from returning to play after multiple concussions, is grounded in the physician's commitment to beneficence and protecting athletes from potential harm. While medical ethics has rightly emphasized the importance of preserving patient autonomy, this principle is not absolute and does not outweigh all other ethical imperatives. A physician's commitment to beneficence and duty to protect his or her patient from harm may occasionally supersede patient autonomy from an ethical perspective.

Conflicts of interest. Ideally, physician reimbursement pertaining to sports-related concussion should be solely derived from patient evaluation, management, and counseling activities. Physicians and other members of concussion management teams (e.g., physical therapists and neuropsychologists) should disclose all financial arrangements that could influence patient care decisions to athletes and parents, including contractual relationships with teams, organizations, or governing bodies, involvement (scientific or financial) in the development of diagnostic or protective equipment, or paid sponsorships. Physicians who have the potential to benefit financially by direct reimbursement or indirectly by reputation from referrals, publicity, or name recognition from treating athletes with concussion should disclose these potential conflicts of interest and must ensure their primary duty is to the health of the athletes.

Physicians employed by athletic teams may find that their duty to an injured athlete may directly conflict with the interests of their employer. In this context, physicians may receive implicit or explicit pressure to prematurely clear athletes to return to play. It is of paramount importance for physicians to affirm clearly that their primary responsibility is to protect the health and well-being of their patients, regardless of financial interests or employment considerations. Failure to prioritize patient well-being represents a breach of ethical and professional conduct. Such action could result in termination of AAN membership, which is reportable to the National Practitioner Databank. ${ }^{26,38}$ Physicians should also be aware that even the perception that they may be unduly influenced by the teams that employ them may result in a detrimental erosion of trust between physicians and their athlete-patients. ${ }^{39}$

Distributive justice. Ideally, all athletes would have access to timely concussion-related medical care from qualified providers trained to evaluate and manage concussion and its complications. However, treatment disparities have been well-documented for many aspects of care delivery in numerous neurologic conditions and concussion care is unlikely to be an exception. ${ }^{40-42}$ Schools and athletic organizations 
should consider the potential financial burden athletes and their families may incur in order to obtain evaluation and treatment of a sports-related brain injury; such costs may prove prohibitive for disadvantaged families. These entities should also ensure that, at a minimum, a concussion evaluation is available to all athletes.

Access to providers familiar with concussion management may be particularly challenging in rural or underserved areas, which may have fewer providers with concussion expertise. Educational models that use videoconferencing technology to train primary care providers to manage complex medical conditions outside their expertise have demonstrated excellent results and may be applied to concussion medicine as a means of improving the quality of concussion care in these communities. ${ }^{43}$

Other types of disparities may also impact access to high-quality resources for concussion prevention and evaluation. For example, athletes (especially those in school districts with few financial resources) may have limited access to protective equipment that could prevent or reduce concussion injury. ${ }^{44,45}$ Baseline and interval neuropsychological testing are increasingly used to monitor athletes for potential cognitive injury. However, it is important to ensure that these tests perform well across culturally and ethnically diverse populations, including athletes who speak English as a second language. ${ }^{46}$ Further work is needed to ensure that neuropsychological testing is valid and generalizable to all athletes.

DISCUSSION Sports-related concussions are a growing public health concern, especially for youth and amateur athletes. Physicians caring for these athletes have an ethical responsibility, grounded in the principles of beneficence and nonmaleficence, to ensure that they safeguard the physical and mental health of their athlete-patients. While autonomy is a fundamental ethical principle, it is not absolute and should not supersede other principles such as beneficence in ethical deliberations surrounding concussion management. It is therefore of paramount importance for physicians to promote informed and shared decisionmaking with athletes, parents, and medical teams that aims to respect patient autonomy while protecting athletes from potential harm. Physicians can accomplish this by providing unbiased information to athletes and their parents about common concussion symptoms as well as the potential short- and long-term risks of single and repetitive head injuries. Physicians need to be aware of how to navigate the ethical and legal impediments to achieving these goals, particularly the numerous potential conflicts of interest.

Overall, the evaluation and management of concussed athletes, as well as concussion research and policy, may benefit from (1) the inclusion of education about concussion pathophysiology, diagnosis, evaluation, and management into neurology residency training programs; (2) wider implementation of baseline cognitive testing, particularly for high-risk athletes, to improve our understanding of the short- and longterm cognitive impact of concussions; and (3) the development of a national concussion registry (optimally with a mandatory reporting scheme) to document more rigorously the incidence, recurrence, and neurologic sequelae of concussion at all levels of play. ${ }^{47}$

In the future, more widespread baseline cognitive testing and the creation of a national concussion database would facilitate monitoring concussion rates and outcomes as various strategies for prevention (i.e., rule changing or modifications to protective equipment) are implemented. These strategies could help identify the threshold at which the number and severity of head injuries leads to irreversible brain injury. They may also help clarify how concussion risk varies with factors like age, sex, pubertal stage, and ethnicity so athletes and parents can make informed decisions about playing contact sports. Additionally, increased baseline testing and a national database will further research into the natural history of the cognitive side effects from concussion, help determine which assessment tools best detect and monitor concussion-related changes, and help assess the prevalence of phenomena like "doctor shopping." Baseline testing may also help reduce bias in the interpretation of results based on preinjury intelligence, language, or cultural differences, thus addressing potential disparities in care. Furthermore, longitudinal data from a prospective registry could eventually facilitate a more comprehensive understanding of the neurocognitive, neurobehavioral, and neuroeconomic consequences that athletes (particularly those in high-risk sports or high-risk positions) face from single and repetitive head injuries.

\section{AUTHOR CONTRIBUTIONS}

Dr. Kirschen: conceptualization of material and drafting and revising the manuscript. Dr. Tsou: conceptualization of material and drafting and revising the manuscript. Ms. Nelson: conceptualization of material and drafting and revising the manuscript. Dr. Russell: conceptualization of material and drafting and revising the manuscript. Dr. Larriviere: conceptualization of material and drafting and revising the manuscript.

\section{ACKNOWLEDGMENT}

The authors thank Drs. Christopher Giza and Jeffrey Kutcher for critiques of earlier versions of this report. The authors also thank the members of the AAN Ethics, Law, and Humanities Committee and AAN staff who participated in development of this report and guidance.

\section{STUDY FUNDING}

No targeted funding reported.

\section{DISCLOSURE}

M. Kirschen received honorarium for authorship in Continuum ${ }^{\circledR}$. A. Tsou reports no disclosures relevant to the manuscript. S. Nelson provided legal counsel for the AAN. J. Russell received authorship royalties from McGrawHill, Continuum, and Lahey Clinic. D. Larriviere was paid as an Associate Editor for Continuum Audio, is an Associate Editor for Continuum and an 
Associate Editor for Neurology Today ${ }^{\circledR}$, and is a paid faculty member for the American Academy for the Advancement of Science. This document is an official position paper of the Ethics, Law, and Humanities Committee, a joint committee of the American Academy of Neurology, American Neurological Association, and the Child Neurology Society. The AAN and Child Neurology Society have endorsed the paper. Go to Neurology.org for full disclosures.

Received October 20, 2013. Accepted in final form March 3, 2014.

\section{REFERENCES}

1. Langlois JA, Rutland-Brown W, Wald MM. The epidemiology and impact of traumatic brain injury: a brief overview. J Head Trauma Rehabil 2006;21:375-378.

2. Frommer LJ, Gurka KK, Cross $\mathrm{KM}$, Ingersoll $\mathrm{CD}$, Comstock RD, Saliba SA. Sex differences in concussion symptoms of high school athletes. J Athl Train 2011;46:76-84.

3. Lincoln AE, Caswell SV, Almquist JL, Dunn RE, Norris JB, Hinton RY. Trends in concussion incidence in high school sports: a prospective 11-year study. Am J Sports Med 2011;39:958-963.

4. Bakhos LL, Lockhart GR, Myers R, Linakis JG. Emergency department visits for concussion in young child athletes. Pediatrics 2010;126:550-556.

5. McCrea M, Kelly JP, Randolph C, Cisler R, Berger L. Immediate neurocognitive effects of concussion. Neurosurgery 2002;50:1032-1040.

6. Guskiewicz KM, Marshall SW, Bailes J, et al. Recurrent concussion and risk of depression in retired professional football players. Med Sci Sports Exerc 2007;39:903-909.

7. Barlow KM, Crawford S, Stevenson A, Sandhu SS, Belanger F, Dewey D. Epidemiology of postconcussion syndrome in pediatric mild traumatic brain injury. Pediatrics 2010;126:374-381.

8. Watanabe T, Elovic E, Zafonte R. Chronic traumatic encephalopathy. PM R 2010;2:671-675.

9. Gavett BE, Cantu RC, Shenton M, et al. Clinical appraisal of chronic traumatic encephalopathy: current perspectives and future directions. Curr Opin Neurol 2011;24:525-531.

10. Gavett BE, Stern RA, McKee AC. Chronic traumatic encephalopathy: a potential late effect of sport-related concussive and subconcussive head trauma. Clin Sports Med 2011;30: 179-188.

11. Talavage TM, Nauman EA, Breedlove EL, et al. Functionallydetected cognitive impairment in high school football players without clinically-diagnosed concussion. J Neurotrauma 2013; 30:1-12.

12. Guskiewicz KM, McCrea M, Marshall SW, et al. Cumulative effects associated with recurrent concussion in collegiate football players: the NCAA concussion study. JAMA 2003;290:2549-2555.

13. American Academy of Neurology. Sports Neurology Survey: Final Report. Minneapolis: American Academy of Neurology; 2012.

14. Giza CC, Kutcher JS, Ashwal S, et al. Summary of evidence-based guideline update: evaluation and management of concussion in sports: report of the Guideline Development Subcommittee of the American Academy of Neurology. Neurology 2013;80:2250-2257.

15. Halstead ME, Walter KD. American Academy of Pediatrics: clinical report: sport-related concussion in children and adolescents. Pediatrics 2010;126:597-615.

16. McCrory P, Meeuwisse WH, Aubry M, et al. Consensus statement on concussion in sport: the 4th International Conference on Concussion in Sport held in Zurich, 2012. Br J Sports Med 2013;47:250-258.
17. Guskiewicz KM, Bruce SL, Cantu RC, et al. National Athletic Trainers' Association position statement: management of sport-related concussion. J Athletic Train 2004;39:280-297.

18. Harmon KG, Drezner JA, Gammons M, et al. American Medical Society for Sports Medicine position statement: concussion in sport. Br J Sports Med 2013;47:15-26.

19. Concussion Treatment and Care Tools Act of 2010, 111th Cong, 2nd Sess. 2010.

20. Protecting Student Athletes from Concussions Act of 2011, 112th Cong, 1st Sess. 2011.

21. National Conference of State Legislatures. Traumatic brain injury legislation. Available at: http://www.ncsl.org/research/ health/traumatic-brain-injury-legislation.aspx. Accessed June 3, 2014.

22. Zackery Lystedt Law. Wash Rev Code Sect 28A.600.190. 2009.

23. AAN Sports Concussion Toolkit. Sports-concussion state laws. Available at: https://www.aan.com/uploadedFiles/ Website_Library_Assets/Documents/3Practice_Management/ 5Patient_Resources/1For_Your_Patient/6_Sports_Concussion_ Toolkit/statelaw.pdf. Accessed June 3, 2014

24. Torres DM, Galetta KM, Phillips HW, et al. Sportsrelated concussion: anonymous survey of a collegiate cohort. Neurol Clin Pract 2013;3:279-287.

25. Privacy of Individually Identifiable Health Information, 45 CFR Sect 164.512(j)(1)(i)(A). 2002.

26. American Academy of Neurology Code of Professional Conduct. Available at: http://www.aan.com/membership/ professionalism-and-disciplinary-program/. Accessed August 25, 2013.

27. McAllister TW, Flashman LA, Maerlender A, et al. Cognitive effects of one season of head impacts in a cohort of collegiate contact sport athletes. Neurology 2012;78:1777-1784.

28. Pennington B. Expectations lose to reality of sports scholarships. New York Times. May 10, 2008. http://www. nytimes.com/2008/03/10/sports/10scholarships.html? pagewanted $=$ all\&_r $=0$. Accessed June 3, 2014.

29. Committee on Bioethics, American Academy of Pediatrics. Informed consent, parental permission, and assent in pediatric practice. Pediatrics 1995;95:314-317.

30. Weithorn LA, Campbell SB. The competency of children and adolescents to make informed treatment decisions. Child Dev 1982;53:1589-1598.

31. Beauchamp TL, Childress JF. Principles of Biomedical Ethics, 6th ed. New York: Oxford University Press; 2009.

32. Shuttleworth-Edwards AB, Radloff SE. Compromised visuomotor processing speed in players of Rugby Union from school through to the national adult level. Arch Clin Neuropsychol 2008;23:511-520.

33. Wall SE, Williams WH, Cartwright-Hatton S, et al. Neuropsychological dysfunction following repeat concussions in jockeys. J Neurol Neurosurg Psychiatry 2006;77:518-520.

34. Field M, Collins MW, Lovell MR, Maroon J. Does age play a role in recovery from sports-related concussion? A comparison of high school and collegiate athletes. J Pediatr 2003;142:546-553.

35. Pellman EJ, Lovell MR, Viano DC, Casson IR. Concussion in professional football: recovery of NFL and high school athletes assessed by computerized neuropsychological testing: part 12. Neurosurgery 2006;58:263-274.

36. Emery CA, Kang J, Shrier I, et al. Risk of injury associated with body checking among youth ice hockey players. JAMA 2010;303:2265-2272.

37. Collie A, Makdissi M, Maruff P, Bennell K, McCrory P. Cognition in the days following concussion: comparison of 
symptomatic versus asymptomatic athletes. J Neurol Neurosurg Psychiatry 2006;77:241-245.

38. American Academy of Neurology Disciplinary Action Policy. Available at: http://www.aan.com/membership/professionalismand-disciplinary-program/. Accessed August 25, 2013.

39. Transcript from NFL Players Association Super Bowl Press Conference. Available at: http://www.nflplayers.com/Articles/ Press-Releases/Transcript-from-NFLPA-Super-Bowl-PressConference/. Accessed August 25, 2013.

40. Dahodwala N, Xie M, Noll E, Siderowf A, Mandell DS. Treatment disparities in Parkinson's disease. Ann Neurol 2009;66: 142-145.

41. Kimball MM, Neal D, Waters MF, Hoh BL. Race and income disparity in ischemic stroke care: Nationwide inpatient sample database, 2002 to 2008. J Stroke Cerebrovasc Dis 2014;23:17-24.

42. Joynt KE, Harris Y, Orav EJ, Jha AK. Quality of care and patient outcomes in critical access rural hospitals. JAMA 2011;306:45-52.
43. Arora S, Thornton K, Murata G, et al. Outcomes of treatment for hepatitis $\mathrm{C}$ virus infection by primary care providers. N Engl J Med 2011;364:2199-2207.

44. Hollis SJ, Stevenson MR, McIntosh AS, Shores EA, Collins MW, Taylor CB. Incidence, risk, and protective factors of mild traumatic brain injury in a cohort of Australian nonprofessional male rugby players. Am J Sports Med 2009;37:2328-2333.

45. Kemp SP, Hudson Z, Brooks JH, Fuller CW. The epidemiology of head injuries in English professional rugby union. Clin J Sport Med 2008;18:227-234.

46. Judd T, Capetillo D, Carrion-Baralt J, et al. Professional considerations for improving the neuropsychological evaluation of Hispanics: a National Academy of Neuropsychology education paper. Arch Clin Neuropsychol 2009; 24:127-135.

47. Institute of Medicine. Sports-related Concussions in Youth: Improving the Science, Changing the Culture. Washington, DC: Institute of Medicine; 2013. 


\section{Neurology}

\section{Legal and ethical implications in the evaluation and management of sports-related concussion}

Matthew P. Kirschen, Amy Tsou, Sarah Bird Nelson, et al.

Neurology 2014;83;352-358 Published Online before print July 9, 2014

DOI 10.1212/WNL.0000000000000613

This information is current as of July 9, 2014

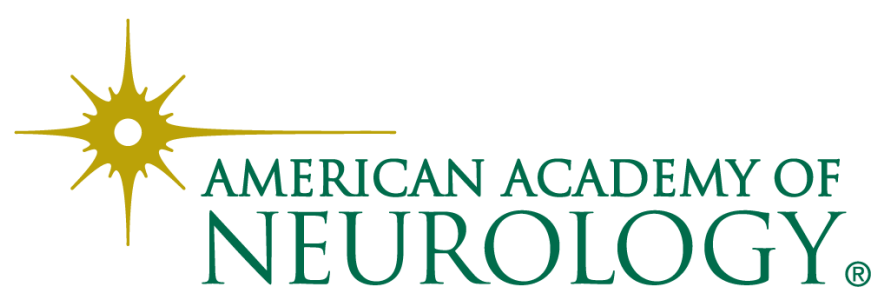




\section{Updated Information \& Services}

\section{Supplementary Material}

\section{References}

Citations

Subspecialty Collections

Permissions \& Licensing

Reprints including high resolution figures, can be found at:

http://n.neurology.org/content/83/4/352.full

Supplementary material can be found at: http://n.neurology.org/content/suppl/2014/07/09/WNL.0000000000000 613.DC1

http://n.neurology.org/content/suppl/2014/07/09/WNL.0000000000000 613.DC2

This article cites 34 articles, 7 of which you can access for free at: http://n.neurology.org/content/83/4/352.full\#ref-list-1

This article has been cited by 2 HighWire-hosted articles: http://n.neurology.org/content/83/4/352.full\#\#otherarticles

This article, along with others on similar topics, appears in the following collection(s):

All Ethics in Neurology/Legal issues

http://n.neurology.org/cgi/collection/all_ethics_in_neurology_legal_iss ues

\section{All Trauma}

http://n.neurology.org/cgi/collection/all_trauma

Brain trauma

http://n.neurology.org/cgi/collection/brain_trauma

Information about reproducing this article in parts (figures,tables) or in its entirety can be found online at:

http://www.neurology.org/about/about_the_journal\#permissions

Information about ordering reprints can be found online:

http://n.neurology.org/subscribers/advertise

Neurology ${ }^{\circledR}$ is the official journal of the American Academy of Neurology. Published continuously since 1951, it is now a weekly with 48 issues per year. Copyright @ 2014 American Academy of Neurology. All rights reserved. Print ISSN: 0028-3878. Online ISSN: 1526-632X.

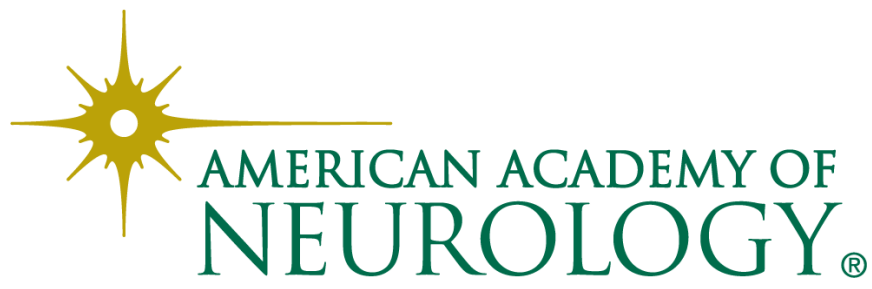

